Article

\title{
Effect of Ozone Treatment on Inactivation of Escherichia coli and Listeria sp. on Spinach
}

\author{
Shreya Wani, Jagpreet K. Maker, Joseph R. Thompson, Jeremy Barnes * and Ian Singleton * \\ School of Biology, Newcastle University, Newcastle upon Tyne, NE1 7RU, UK; \\ E-Mails: shrenrique@gmail.com (S.W.); jagmaker@gmail.com (J.K.M.); \\ j.thompson5@newcastle.ac.uk (J.R.T.) \\ * Authors to whom correspondence should be addressed; E-Mails: jerry.barnes@newcastle.ac.uk (J.B.); \\ ian.singleton@ncl.ac.uk (I.S.); Tel.: +44-0-191-243-0871 (J.B.); +44-0-191-208-3043 (I.S.).
}

Academic Editor: Pascal Delaquis

Received: 15 February 2015 / Accepted: 17 March 2015 / Published: 26 March 2015

\begin{abstract}
The efficacy of "gaseous" ozone in reducing numbers and re-growth of food-borne pathogens, (Escherichia coli and Listeria spp.), on leafy salads was investigated using spinach. A preliminary in vivo study showed 1-log reduction in six strains of $E$. coli and two species of Listeria spp. on spinach exposed to $1 \mathrm{ppm}$ ozone for $10 \mathrm{~min}$. A range of ozone treatments were explored to deliver optimal bacterial inactivation while maintaining the visual appearance (color) of produce. Exposure to a higher ozone concentration for a shorter duration (10 ppm for $2 \mathrm{~min}$ ) significantly reduced E. coli and Listeria spp. viable counts by $1-\log$ and the pathogens did not re-grow following treatment (over a nine-day storage period). Impacts of 1 and $10 \mathrm{ppm}$ ozone treatments were not significantly different. Approximately $10 \%$ of the pathogen population was resistant to ozone treatment. We hypothesized that cell age may be one of several factors responsible for variation in ozone resistance. E. coli cells from older colonies demonstrated higher ozone resistance in subsequent experiments. Overall, we speculate that gaseous ozone treatment constitutes the basis for an alternative customer-friendly method to reduce food pathogen contamination of leafy produce and is worth exploring on a pilot-scale in an industrial setting.
\end{abstract}

Keywords: gaseous ozone; E. coli; Listeria spp. 


\section{Introduction}

In addition to reducing produce spoilage, an increased incidence in the outbreaks of microbial borne diseases associated with the consumption of raw leafy produce have added to the need to find alternative methods to reduce microbial loads [1]. All types of leafy produce have the potential to harbor pathogens, such as Escherichia coli, Listeria monocytogenes, Shigella spp., and Salmonella spp., which are ultimately responsible for the majority of foodborne outbreaks [2,3]. Contamination of fresh produce with pathogens can occur either pre-harvest and/or post-harvest. Pre-harvest sources of pathogens generally include organic fertilizers, irrigation water, and soil, whereas post-harvest sources mainly result from handling procedures including equipment, transport vehicles, and containers [4].

A recent investigation of retail leafy salads revealed contamination of a significant proportion with E. coli and L. monocytogenes [5]. E. coli is a Gram-negative, facultative anaerobic member of the Enterobacteriaceae family. It is commonly present in gastrointestinal tract of humans and animals including deer, cattle, and pigs [6]. Although most E. coli are harmless to humans, epidemiological research has documented that intake of leafy produce contaminated with E. coli O157:H7 and variants thereof, with a dose as low as 10 cells, can pose severe threat to human health [7]. E. coli that cause disease are categorized on the basis of pathogenic mechanisms, virulence, and clinical syndrome. For example, E. coli $\mathrm{O} 157: \mathrm{H} 7$ belongs to the enterohaemorrhagic (EHEC) group [8]. Infection with E. coli O157:H7 causes major outbreaks particularly associated with raw leafy produce [5]. Although leaf surfaces are not a suitable environment for E. coli, it can survive both harsh field and post-harvest storage conditions [5].

L. monocytogenes is a Gram-positive, facultative anaerobic, non-spore forming rod, which is capable of growing at low temperatures. This pathogen is widely present in soil, plant, and water surfaces [9]. It causes less than one percent of foodborne diseases, but it is responsible for causing listeriosis in human [10]. In healthy individuals, the main symptoms are fever and diarrhea, whereas in pregnant women, L. monocytogenes causes septicaemia, meningitis, abortion, or stillbirth [5,10]. L. monocytogenes is capable of growing at refrigeration temperatures and also surviving in food-processing sites [5].

Microbial contamination of fresh produce by pathogenic microbes not only poses significant risk to public health but also affects the industry financially by resulting in costly product recalls. For example, the recent Shiga toxin-producing E. coli $\mathrm{O} 157$ outbreak in watercress is estimated to have required the recall of 200,000 items in the United Kingdom [11]. Foodborne outbreaks are common in many countries. This could be due to the pathogens developing resistance to traditional sanitizing agents, thus posing a hazard to the safety of the food supply [12].

Ozone has been successfully used as a principal sanitizer for treating drinking and municipal waters for 100 years, but recently gained attention in the food and agriculture industry [13]. It is well known for its strong oxidizing capacity and has been recognized as a powerful antimicrobial agent, reacting with organic substances approximately 3000 times quicker than chlorine [14]. Ozone is capable of inactivating microorganisms including both Gram positive and Gram negative bacteria, bacterial spores, fungi, fungal spores, viruses, and protozoa [15]. In 1997, the United States Food and Drug Administration (US-FDA) in union with an expert panel granted ozone as GRAS (Generally Recognised as Safe) status [16], and in 2003, it received formal approval from the US-FDA as a "direct contact food sanitizing agent" [17]. One of the major advantages of ozone treatment is the fact the gas leaves no detectable 
residues in/on treated products, as ozone rapidly decomposes into oxygen unlike other sanitizers used in the food processing industry [13].

Given the importance of controlling pathogen contamination of leafy fresh produce, the present study aimed to determine the antimicrobial effects of ozone for the control of different strains of $E$. coli and Listeria spp. and to observe the regrowth of these pathogenic bacteria on ozone-treated produce during storage of produce for nine days at $4{ }^{\circ} \mathrm{C}$. Previous studies have shown the impact of ozone on pathogens $[14,18,19]$ but have not investigated re-growth after treatment. We also wanted to use ozone levels that did not damage produce, i.e., we investigated commercially-relevant ozone levels for produce treatment. Previous research has shown that not all pathogens are killed by ozone treatment [20] and another objective of this work was to establish why this may occur. Accordingly, we examined the effect of cell age on E. coli resistance to ozone. Spinach was artificially contaminated by inoculating with E. coli or Listeria spp. before ozone treatment. Six different strains of non-pathogenic $E$. coli were used as a representative model for E. coli $\mathrm{O} 157: \mathrm{H7}$, as there have been no reports suggesting significant differences in growth pattern and survival strategy between non-pathogenic E. coli and pathogenic E. coli O157:H7 [21]. In addition, L. innocua and L. seeligeri were used as surrogates for L. monocytogenes because these offer safe non-pathogenic alternatives for experimental purposes whilst exhibiting similar growth characteristics and behavior on leafy produce as L. monocytogenes [20,22].

\section{Results and Discussion}

\subsection{Effect of Ozone Exposure on E. coli and Listeria sp. in Vitro}

Colony numbers (CFU) of E. coli K12 and L. innocua in vitro were significantly reduced $(p<0.05)$ by all ozone treatments (Figure 1), even at the lowest level used (1 ppm for $10 \mathrm{~min}$ ). Less than 1-log reduction was achieved when colonies on agar were exposed to $1 \mathrm{ppm}$ ozone for $10 \mathrm{~min}$, but more than 1-log reduction was achieved when both the strains of food pathogens were treated with ozone concentrations of 10 and 50 ppm. Similar results were observed by Alwi [18], when E. coli O157, L. monocytogenes, and Salmonella typhimurium were treated in vitro with $0.1,0.3,0.5$, and $1.0 \mathrm{ppm}$ ozone concentration for exposure times of $0.5,3,6$, and $24 \mathrm{~h}$, respectively. They also observed increases in ozone concentration, and exposure time increased the antibacterial activity.

Interestingly, the agar based in vitro assay on both Gram-positive and Gram-negative pathogens showed no significant difference in colony counts between $10 \mathrm{ppm}$ and $50 \mathrm{ppm}$ ozone concentration treatment. This is possibly due to cells being physically protected by others on the surface of the agar plates, i.e., when the cells are spread on agar some cells may not be present as individuals but as groups that provide physical protection; thus, this could reduce the effectiveness of ozone treatment [18]. Alternatively, some cells may have an intrinsic resistance to ozone exposure perhaps due to their age and exposure to stress (see below Section 2.6). Fan and colleagues [20] reported that the maximum inactivation of L. innocua cells was observed in less than $2 \mathrm{~h}$ and inactivation reached a plateau after $4 \mathrm{~h}$ when treated with gaseous ozone in vitro. 
(A) Escherichia coli $\mathrm{K} 12$

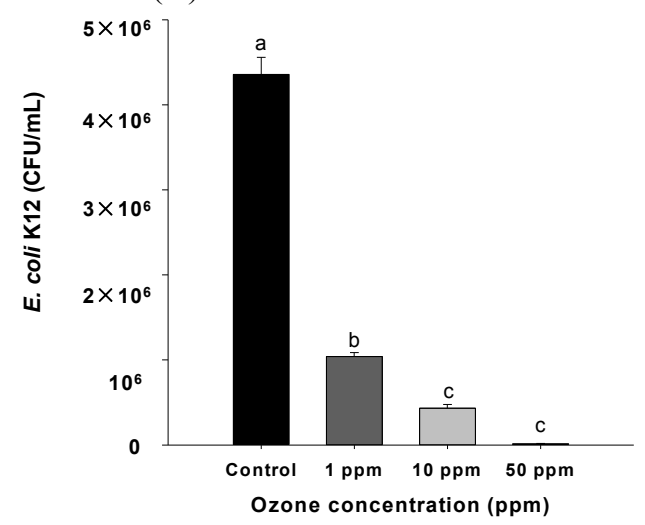

(B) Listeria innocua

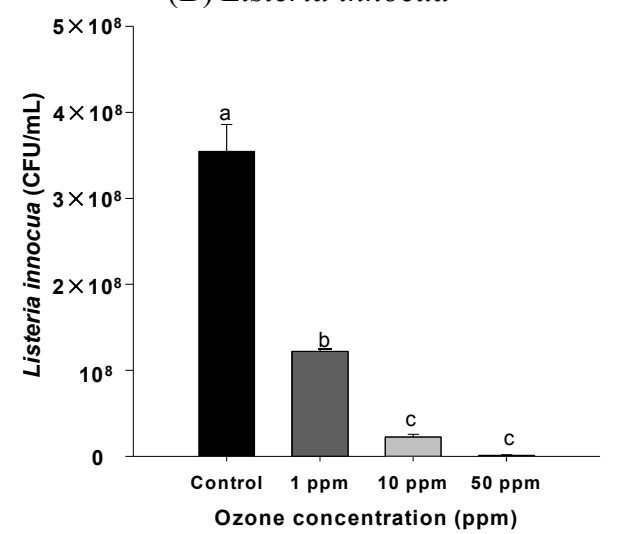

Figure 1. Impacts of ozone treatment on (A) E. coli $\mathrm{K} 12$ and $(\mathbf{B})$ L. innocua $(\mathrm{CFU} / \mathrm{mL})$ grown on agar plates. The treatment chamber was ventilated with 1, 10, or 50 ppm ozone for 10 min. Controls were exposed to "clean air". Values represent the mean ( \pm Standard Error) of measurements made on three independent plates per treatment. Bars with different letters are statistically significantly different $(p<0.05)$.

\subsection{Optimization of the Concentration and Duration of Ozone Exposure Levels to Treat Spinach without Causing Visual Damage}

The visual appearance and freshness of leafy produce has been the main judging criteria for quality distinction at purchase or consumption [23]. No visual ozone damage was observed when spinach was treated with 1 ppm gaseous ozone, but higher levels, e.g., $10 \mathrm{ppm}$ for $10 \mathrm{~min}$, caused significant visual blemishes and discoloration to spinach (Figure 2A). Similar results were previously observed on fresh produce like lettuce, spinach, and rocket leaves when treated with similar ozone concentrations [24]. Figure 2B illustrates ozone injury/visual damage on spinach when exposed to $10 \mathrm{ppm}$ ozone concentration for $10 \mathrm{~min}$. It is evident that the impact of ozone treatment on the quality of leafy produce is dependent on concentration; it may be beneficial up to a certain level to apply ozone, whereas after a critical level acceleration of browning responses will result in inferior quality.

No visual ozone damage was observed when spinach was exposed to higher concentrations such as 10,15 , and 20 ppm ozone for shorter durations (Table 1). Ozone treated produce visually looked as fresh and as attractive as untreated produce (control) after seven days of storage. Ozone injury/visible damage were observed on spinach when exposed to $25 \mathrm{ppm}$ ozone concentration for all durations examined (30 s, $45 \mathrm{~s}$, and $2 \mathrm{~min})$.

Subsequent experiments examined the effect of varying ozone levels and exposure times on pathogens inoculated onto spinach surfaces.

Table 1. The maximum ozone exposure levels that can be applied on spinach without causing visible damage.

\begin{tabular}{ccccc}
\hline \multicolumn{5}{c}{ Duration of the Exposure of Spinach } \\
\hline Ozone concentration & $10 \mathrm{ppm}$ & $15 \mathrm{ppm}$ & $20 \mathrm{ppm}$ & $25 \mathrm{ppm}$ \\
Time & $2 \mathrm{~min}$ & $45 \mathrm{~s}$ & $30 \mathrm{~s}$ & Damaged at 30 s, 45 s and 2 min \\
\hline
\end{tabular}




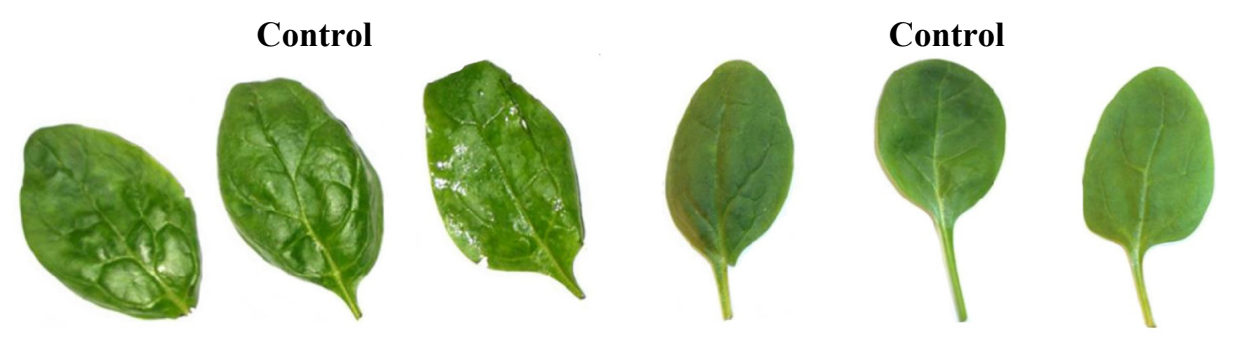

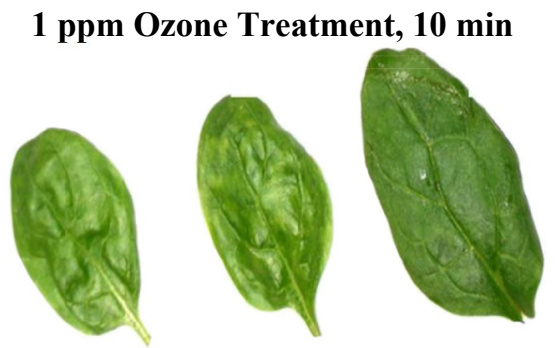

(A)

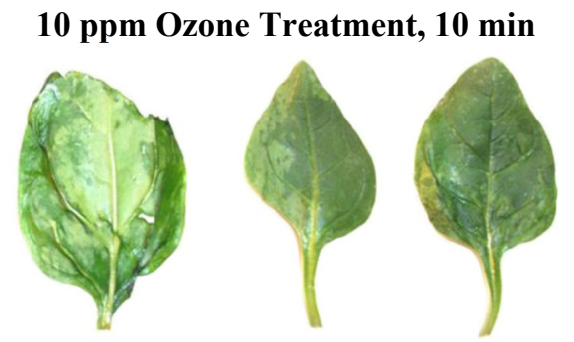

(B)

Figure 2. (A) Impact of ozone exposure levels on visual quality of spinach when treated at $1 \mathrm{ppm}$ ozone concentration for $10 \mathrm{~min}$ and (B) Ozone injury/visual damage on spinach when exposed to $10 \mathrm{ppm}$ ozone concentration for $10 \mathrm{~min}$.

\subsection{Effect of Ozone Exposure (1 ppm for $10 \mathrm{~min}$ ) on Different Strains of E. coli Inoculated onto Spinach Leaf Surfaces}

Colony numbers (CFU) of all six strains of E. coli, i.e., E. coli O157:K88a, E. coli O25:H4, E. coli O128:K67, E. coli K12, E. coli O55:K59, and E. coli O104:H12 obtained from ozone exposed leaves were significantly reduced $(p<0.05)$ compared with non-ozone exposed controls (Figures 3 and 4 ). No E. coli colonies were isolated from non-inoculated spinach leaves. In the past, gaseous ozone treatment at 1 ppm for 5 min showed 3-5 $\log _{10}$ reduction of E. coli O157:H7 on spinach after $24 \mathrm{~h}$ of storage [25]. An experiment conducted in vacuum-cooling in combination with ozone gas (10 ppm for up to three days) showed $1.4 \log _{10}$ reduction of E. coli $\mathrm{O} 157: \mathrm{H} 7$ on spinach [17]. Gaseous ozone treatment has also proved to be effective in reducing E. coli on many products like lettuce [14], parsley [17], mushrooms [19], blueberries [26], and dried figs [27]. Singh et al. [14] reported that the bactericidal effect of ozone against E. coli $\mathrm{O} 157: \mathrm{H} 7$ increased with exposure time and ozone concentration. For example, they observed 0.79-1.79 $\log _{10} \mathrm{CFU} / \mathrm{g}$ reduction of $E$. coli $\mathrm{O} 157: \mathrm{H} 7$ population on lettuce when exposed to ozone for $15 \mathrm{~min}$. However, ozone treatment for 5 or $10 \mathrm{~min}$ did not decrease the E. coli $\mathrm{O} 157: \mathrm{H} 7$ population. 


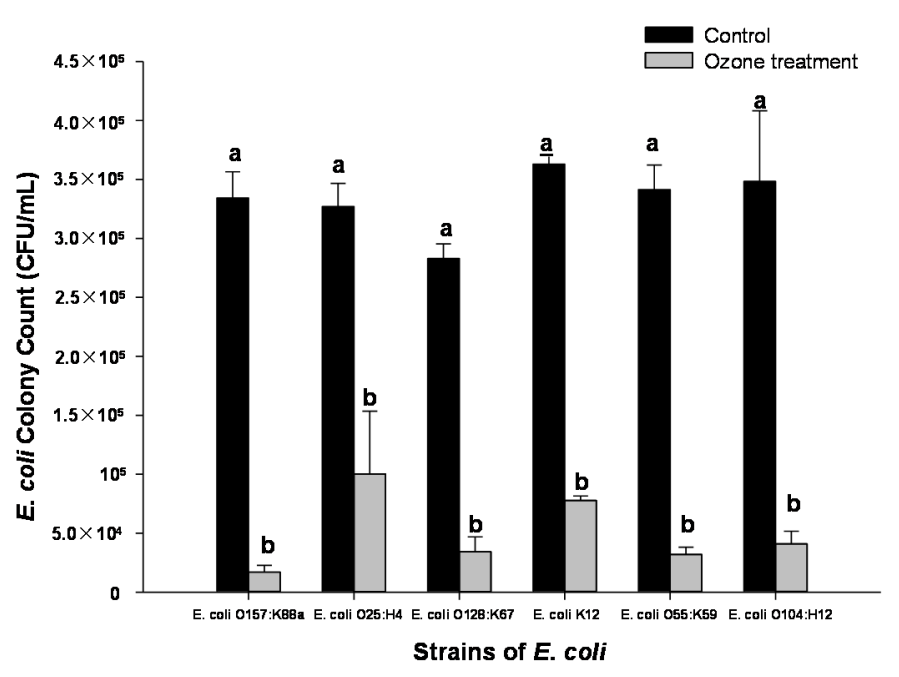

Figure 3. Impacts of ozone-enrichment on six strains of E. coli inoculated onto the surface of spinach leaves. Leaves were either treated with 1 ppm ozone concentration (grey bar) or untreated (black bar) for $10 \mathrm{~min}$. Values represent means ( \pm Standard Error) of measurements made on three independent spinach leaves per treatment. Bars with different letters are significantly different $(p<0.05)$.

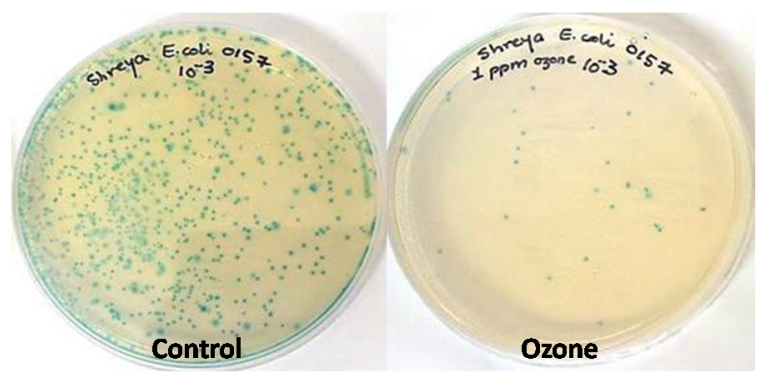

Figure 4. Colonies of E. coli O157:K88a on Tryptone Bile X-Glucuronide (TBX) agar recovered from leaves after being exposed to either "clean" air (control) or 1 ppm ozone concentration for $10 \mathrm{~min}$.

\subsection{Impact of Ozone Treatment on Listeria innocua and L. seeligeri Inoculated onto Spinach Leaves}

In the present study, L. innocua and L. seeligeri were used as microbial surrogate of L. monocytogenes, as they are useful indicators of contamination and have also demonstrated behavior similar to L. monocytogenes on fresh produce [28]. Results from spinach artificially contaminated with L. innocua and L. seeligeri treated with $1 \mathrm{ppm}$ ozone for an exposure time of $10 \mathrm{~min}$ showed a 1-log reduction in colony count compared with the untreated control (Figure 5). Karaca and his colleague [17] reported a reduction in L. innocua of $1.14 \log _{10} \mathrm{CFU} / \mathrm{g}$ on flat-leaved parsley when treated with high ozone concentration of $950 \mathrm{ppm}$ for $20 \mathrm{~min}$. Similar results have been shown by previous research on mushrooms, alfalfa sprouts, alfalfa seeds, and lettuce [19]. The growth of L. innocua and L. seeligeri on spinach remained significantly reduced after Day 9 of storage (Figure 5). This may be due to the interactions between the natural background microflora of spinach and L. innocua, which can affect its growth and survival [22]. O'Berine and his colleague [22] reported that lactic acid bacteria and mixed population of natural microflora isolated from shredded lettuce reduced L. innocua growth in model 
media. Rodgers and colleagues [19] demonstrated complete inactivation of L. monocytogenes on lettuce during nine days of storage when treated with 3 ppm ozone for $3 \mathrm{~min}$.
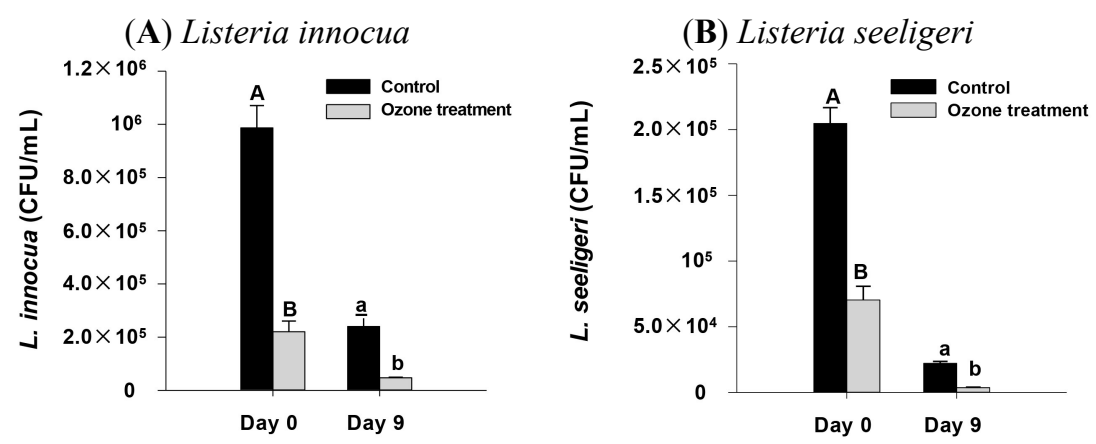

Figure 5. Impacts of ozone-enrichment on (A) L. innocua and (B) L. seeligeri inoculated onto the surface of spinach leaves. Leaves were either treated with 1 ppm ozone concentration (grey bar) or untreated (black bar) for $10 \mathrm{~min}$. Colonies were enumerated either directly after the treatments, i.e., Day 0 or after nine days of storage. Values represent means ( \pm Standard Error) of measurements made on three independent spinach leaves per treatment. Bars with different letters are significantly different $(p<0.05)$.

\subsection{Effect of Higher Ozone Treatment on E. coli and Listeria sp. Inoculated onto Spinach Leaf Surface}

Results of spinach artificially contaminated with two strains of E. coli (E. coli O157:K88a and E. coli $\mathrm{O} 25: \mathrm{H} 4)$ and Listeria (L. innocua and L. seeligeri) treated with $10 \mathrm{ppm}$ of ozone concentration for $2 \mathrm{~min}$ are shown in Figure 6. For E. coli O157:K88a and E. coli O25:H4, ozone treatment significantly $(p<0.05)$ reduced counts by $1-\log$ compared with the untreated control (Figure 6A). Ozone had less than 1-log effect on L. innocua and L. seeligeri (Figure 6B). Awli [18] achieved reduction of 2.89 and $3.06 \log _{10}$ for E. coli $O 157$ and L. monocytogenes, respectively, on bell pepper when exposed to $9 \mathrm{ppm}$ ozone for $6 \mathrm{~h}$. Their work met the standards for an antimicrobial agent by attaining a minimum of $2 \log _{10}$ reduction [18]. Similar reductions were observed from application of 5 ppm ozone for 3 min on whole tomato [29]. When results from this work (on leafy produce) are compared with other hardy produce, it appears that ozone treatment was less successful. This is most probably due to the delicate nature of leafy produce, which limits the use of increased ozone concentration and exposure time (results from Section 2.2). In addition, the results obtained from this treatment, i.e., $10 \mathrm{ppm}$ for 2 min were not significantly more effective in reducing bacterial viable counts in comparison to previous ozone treatment used in this study, i.e., $1 \mathrm{ppm}$ for $10 \mathrm{~min}$ (from Sections 2.3 and 2.4).

Ozone inactivates bacterial cells by the progressive oxidation of important cellular constituents [17], and suggestions for the principal target of ozonation include the bacterial cell surface. Bacterial cell death was observed as a consequence of a ruptured cell membrane and as a result of disintegration of cell wall to function as a barrier $[17,18,20]$. E. coli, a Gram-negative bacterium, is more susceptible to ozone treatment because it has a thin peptidoglycan lamella that is covered by an outer membrane made of polysaccharides and lipoproteins [30]. In contrast, some studies claimed that Gram-negative bacteria were more resistant to ozone treatment as compared with Gram-positive bacteria [31]. Results from this study show that ozone treatment was effective in both E. coli and Listeria spp. inactivation but 
Listeria spp. were slightly more resistant. These results are in line with Yuk and colleagues [19], who showed that $E$. coli $\mathrm{O} 157: \mathrm{H} 7$ is more sensitive than Listeria monocytogenes.

(A) E. coli

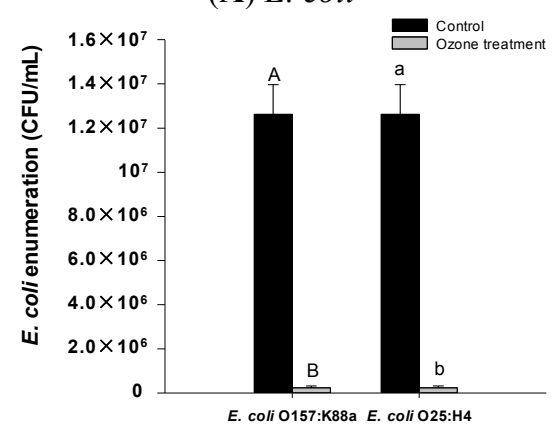

(B) Listeria sp.

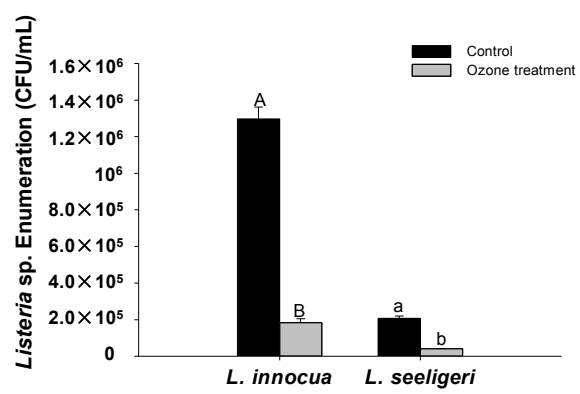

Figure 6. Impacts of increased levels of ozone exposure on two strains of (A) E. coli and (B) Listeria sp. inoculated onto the surface of spinach leaves. Leaves were either treated with $10 \mathrm{ppm}$ ozone concentration (grey bar) or untreated (black bar) for $2 \mathrm{~min}$. Values represent means $( \pm$ Standard Error) of measurements made on three independent spinach leaves per treatment. Bars with different letters are significantly different $(p<0.05)$.

To investigate the after effects of the ozone treatment on pathogen growth, artificially contaminated spinach was stored at $7{ }^{\circ} \mathrm{C}$ for nine days. Figure 7 shows that populations of both E. coli (E. coli O157:K88a and E. coli O25:H4) and Listeria sp. (L. innocua and L. seeligeri) after nine days of storage did not regrow, as a significant reduction in number of colonies was observed in comparison with the untreated control. However, effect of higher ozone treatment on pathogen recovery did not show a significant difference in count as compared with treatment with lower ozone concentration.

\subsection{Effect of Age on Ozone Resistance of E. coli O157:K88a in Vitro}

Throughout the study, we observed that a certain proportion of cells survived ozone exposure and we were interested to make initial investigations into potential ozone resistance mechanisms. E. coli cells of increasing colony age were exposed to ozone (in vitro) and results demonstrated a clear increase in ozone resistance of E. coli O157:K88a with increasing colony age. For example, survival of E. coli O157:K88a was observed to be greater (approximately 15\%) after five days of growth compared with the day 1 time point. Survival levels increased even further by Day 7 (Figure 8) suggesting that cells in older bacterial colonies are more ozone resistant than cells from younger colonies. This is possibly because the older E. coli cells may to be in their long-term stationary phase (fifth phase of bacterial growth cycle that survives on the nutrient released by the dead population of bacteria). These older cells can survive external stress unlike the younger cells (probably in first or second phase of bacterial growth cycle) and can remain viable for months or even years once they enter long-term stationary phase [32]. This stationary phase is dominated by the accumulation of the sigma factor RpoS [32]. The entire cellular physiology of $E$. coli is influenced by RpoS that directly or indirectly affects the expression of $10 \%$ of the $E$. coli genes. These genes are involved in morphological variations within the cell and responsible for increasing resistance during numerous stress conditions, e.g., oxidative stress, osmotic stress, heat shock, etc. [32]. 
(A) E. coli

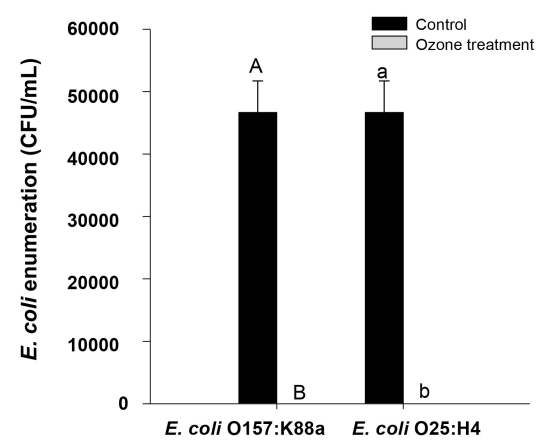

(B) Listeria sp.



Figure 7. Impacts of ozone-enrichment on two strains of (A) E. coli and (B) Listeria sp. inoculated onto the surface of spinach leaves. Leaves were either treated with $10 \mathrm{ppm}$ ozone concentration (grey bar) or untreated (black bar) for $2 \mathrm{~min}$. Colonies were enumerated after nine days of storage. Values represent means ( \pm Standard Error) of measurements made on three independent spinach leaves per treatment. Bars with different letters are significantly different $(p<0.05)$.

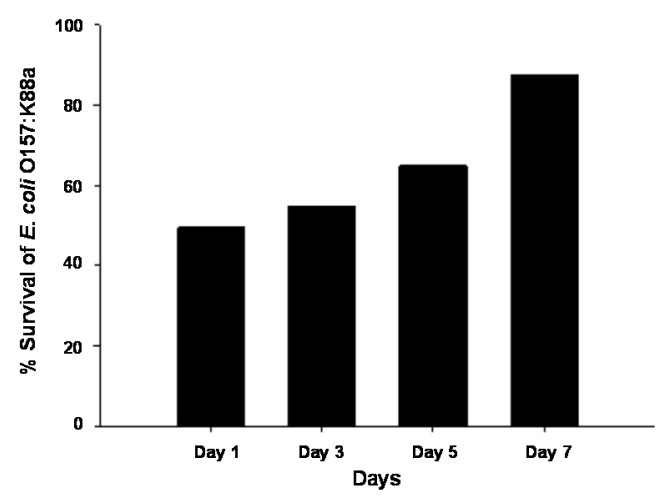

Figure 8. Survival of cells obtained from different colony ages of E. coli O157:K88a exposed to $10 \mathrm{ppm}$ ozone concentration for $2 \mathrm{~min}$. After ozone exposure, the culture plates were maintained at $37^{\circ} \mathrm{C}$ for seven days.

\section{Experimental Section}

\subsection{Ozone Fumigation System}

A purpose designed ozone fumigation system (Figure 9) was housed in a fume hood and constructed of stainless steel (diameter $35 \mathrm{~cm}$ ). An inlet pipe was used to add ozone generated by electric discharge from oxygen (model SGA01 Pacific Ozone Technology Inc., Brentwood, CA, USA), and the introduction of ozone was manually controlled via stainless steel needle valves/gap flow meters. Once the desired ozone concentration was achieved, Petri plates/produce to be exposed to ozone was placed at the bottom of the system and the fumigation system closed with the Pyrex cover (Figure 9). The ozone concentration in the system was recorded using a photometric analyzer (model 450, manufactured by Advanced Pollution Instrumentation Division, 9480 Carroll Park Drive, San Diego, CA, USA). The ozone monitor employed in these studies was serviced weekly and calibrated routinely against standards using a Dasibi 1008PC unit. 




Figure 9. Ozone fumigation system.

\subsection{Assessing the Impact of Ozone Treatment on Food Pathogens E. coli and L. innocua in Vitro}

E. coli $\mathrm{K} 12$ and L. innocua were obtained from a culture collection maintained by Geneius Laboratories Ltd. (44 Colbourne Crescent, Nelson Park, Cramlington, UK). These cultures were sub-cultured by spread plating on Nutrient agar (NA) and Agar Listeria according to Ottaviani and Agosti (ALOA) agar plates, respectively. A single colony was isolated from each culture plate after incubation at $37^{\circ} \mathrm{C}$ for $24 \mathrm{~h}$ and $30{ }^{\circ} \mathrm{C}$ for $48 \mathrm{~h}$, respectively, and transferred to minimum recovery diluent (MRD). A standardized concentration of $10^{4}$ cells per $\mathrm{mL}(100 \mu \mathrm{L})$ of each culture was spread onto sterile NA and ALOA agar plates, respectively. These plates were then either exposed to $1 \mathrm{ppm}, 10 \mathrm{ppm}, 50 \mathrm{ppm}$ ozone concentration, or charcoal filtered "clean air" (controls) for $10 \mathrm{~min}$ at room temperature. After treatment, NA and ALOA agar plates were incubated at $37^{\circ} \mathrm{C}$ for $24 \mathrm{~h}$ and $30^{\circ} \mathrm{C}$ for $48 \mathrm{~h}$, respectively. The number of colonies produced on control plates (non-ozone exposed) were compared with the numbers found on ozone-treated plates based on three replicate observations.

\subsection{Optimization of Ozone Exposure Levels (Concentration and Duration) to Treat Leafy Salads without Causing Visual Damage to Produce}

This experiment focused on optimizing the concentration and duration of ozone exposure to which fresh produce could be exposed without causing visible damage/deterioration. To determine the impact on visual quality of the produce, baby spinach was received from Vitacress Ltd. (Hampshire, UK) and then exposed to 1, 10, 25, $50 \mathrm{ppm}$ ozone or "clean air" (controls) for varying periods of time (1-60 min). Following exposure to ozone, the produce was then packed in a sterile self-seal bag and maintained at $4{ }^{\circ} \mathrm{C}$ in dark conditions. Ozone injury was assessed visually by comparing ozone exposed produce with control (non-ozone exposed) produce every alternate day for seven days.

\subsection{Ozone Resistance of Different Strains of E. coli: Inoculation of E. coli onto Spinach Leaves and} Ozone Exposure Conditions

Six strains of E. coli (E. coli O157:K88a, E. coli $\mathrm{O} 25: \mathrm{H} 4$, E. coli $\mathrm{O} 128: \mathrm{K} 67$, E. coli K12, E. coli O55:K59, and E. coli O104:H12) were obtained from a culture collection maintained by Geneius Laboratories Ltd. (Nelson Park, Cramlington, UK). Cultures were stored at $4{ }^{\circ} \mathrm{C}$ on Luria-Bertani (LB) 
agar plates, and activated in LB broth at $37^{\circ} \mathrm{C}$. Baby-leaf spinach was purchased from a local retailer and aseptically cut into discs measuring $1.13 \mathrm{~cm}^{2}$ using a sterile cork borer. A suspension of E. coli (overnight culture, $10^{8}-10^{9} \mathrm{CFU} / \mathrm{mL}$ LB broth) was applied directly to the leaf disc in $300 \mu \mathrm{L}$ aliquots, and then the inoculated leaves were stored overnight at $7{ }^{\circ} \mathrm{C}$ to mimic produce storage conditions and to allow attachment of $E$. coli to the leaf surface. Inoculated leaves were either exposed to $1 \mathrm{ppm}$ ozone or charcoal filtered "clean air" for $10 \mathrm{~min}$ at room temperature. To determine the number of E. coli remaining (control and ozone exposed), the leaf discs were vigorously shaken in MRD for 2 min and then serially diluted using MRD, followed by pour plate technique using Tryptone Bile X-Glucuronide (TBX) agar plates. Plates were incubated at $44^{\circ} \mathrm{C}$ for $24 \mathrm{~h}$, and presumptive colonies were counted on the basis of three replicate observations.

\subsection{Impact of Ozone Treatment on L. innocua and L. seeligeri Inoculated onto Spinach Leaves}

Two strains of Listeria (L. innocua and L. seeligeri) were obtained from a culture collection maintained by Geneius Laboratories Ltd. Cultures and stored at $4{ }^{\circ} \mathrm{C}$ on ALOA agar plates. Spinach leaves were then aseptically cut into discs measuring $1.13 \mathrm{~cm}^{2}$ using a sterile cork borer. A suspension of Listeria $\mathrm{sp}$. $\left(10^{7}-10^{8} \mathrm{CFU} / \mathrm{mL}\right.$ MRD) was applied directly to the leaf disc in $300 \mu \mathrm{L}$ aliquots, and the inoculated leaves were maintained at $7{ }^{\circ} \mathrm{C}$ to mimic produce storage conditions for $2 \mathrm{~h}$ to allow attachment of Listeria sp. to the leaf surface. Inoculated leaves were either exposed to $1 \mathrm{ppm}$ ozone or charcoal filtered "clean air" for $10 \mathrm{~min}$ at room temperature and survival rate enumerated (see below). For determining the survival and growth of Listeria sp. during storage, a proportion of the treated and untreated inoculated leaves were maintained at $7{ }^{\circ} \mathrm{C}$ for a further nine days. The number of colonies remaining (control and ozone exposed) on Day 0 and Day 9 was determined by vigorously shaking the leaf disc in MRD for 2 min after $1 \mathrm{~h}$ incubation at room temperature, and then serially diluting in MRD followed by standard spread technique on ALOA agar plates. Plates were incubated at $30{ }^{\circ} \mathrm{C}$ for $48 \mathrm{~h}$, and colonies were counted.

\subsection{Modified Ozone Fumigation System-Delivery of High Ozone Concentrations for Short Time} Durations (Seconds)

A modified ozone fumigation system was engineered to improve the application of ozone to produce surfaces, and to reduce the time required to build up the desired ozone concentrations needed for produce treatment. The aim was to develop a system allowing application of higher ozone concentrations for shorter durations to achieve better bacterial kill without damaging the produce. This system was developed after discussions/meetings with industrial partners who ideally wanted to be able to expose produce to ozone quickly during their harvest and processing procedures. The modified ozone exposure apparatus was housed in a fume hood and constructed from $20 \mathrm{~cm}^{2}$ Perspex. Produce was placed on a steel mesh in a $2 \mathrm{~cm}$ deep tray within the box and produce was then exposed to ozone once the desired concentration was achieved (Figure 10). An inlet pipe was used to add ozone generated by electric discharge from oxygen, with the introduction of ozone controlled manually. The ozone concentration was recorded by a photometric analyzer (model 450, manufactured by Advanced Pollution Instrumentation Inc., San Diego, CA, USA). The ozone monitor employed in these studies was serviced routinely. 

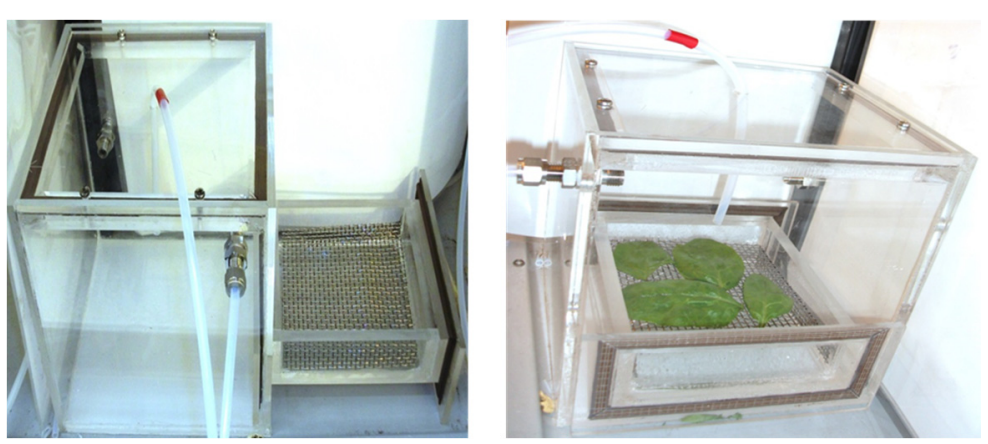

Figure 10. Modified ozone fumigation system.

\subsection{Exploration of Higher Ozone Exposure Levels to Treat Spinach without Causing Visual Damage}

This experiment aimed to determine the highest ozone concentration and exposure time that could be used on organic baby spinach without causing visible damage/deterioration to the produce. Produce was exposed to 10, 15, 20, 25 ppm ozone or "clean air" (controls) for varying periods of time ranging from $30 \mathrm{~s}$ to $2 \mathrm{~min}$. Following exposure to ozone, produce was then packed in a sterile self-seal bag and maintained at $4{ }^{\circ} \mathrm{C}$ in the dark. Ozone injury was assessed visually by comparing ozone exposed produce with control (non-ozone exposed) produce every alternate day for seven days.

\subsection{Impact of Higher/Increased Ozone Concentrations on Two Strains of E. coli and Listeria Inoculated onto Spinach Leaves}

This experiment aimed to use the highest ozone exposure levels that did not cause produce damage (data obtained from Section 3.7-Result Section 2.2) to try and achieve higher reductions in pathogenic bacteria on the surface of baby spinach leaves. Two strains of E. coli (E. coli O157:K88a and E. coli O25:H4) and Listeria (L. innocuous and L. seeligeri) were inoculated onto spinach leaves as described in Sections 3.4 and 3.5, respectively. Inoculated leaves were either treated with $10 \mathrm{ppm}$ ozone concentration or charcoal filtered "clean air" for $2 \mathrm{~min}$. The number of E. coli and Listeria sp. remaining (control and ozone exposed) was determined as described above (Sections 3.4 and 3.5).

To determine the impact of highest ozone exposure levels on the survival and growth of $E$. coli (E. coli $\mathrm{O} 157: \mathrm{K} 88 \mathrm{a}$ and E. coli $\mathrm{O} 25: \mathrm{H} 4$ ) and Listeria (L. innocua and L. seeligeri) during storage, the inoculated leaves were treated as mentioned in Section 3.5. After the treatment, inoculated and control leaves were maintained at $7{ }^{\circ} \mathrm{C}$ for nine days. The number of colonies remaining (control and ozone exposed) on day 9 was determined as mentioned in Section 3.5.

\subsection{Age Effects on Ozone Resistance of E. coli in Vitro}

To determine whether cell age affected the ozone resistance of the bacteria, a colony of E. coli O157:K88a obtained from a culture collection maintained by Geneius Laboratories Ltd. was sub-cultured onto NA plates and incubated at $37^{\circ} \mathrm{C}$ for seven days. A single colony was isolated on the first, third, fifth, and seventh day of the incubation and transferred to MRD. A standardized concentration of $10^{4}$ cells per $\mathrm{mL}(100 \mu \mathrm{L})$ of each cell age was spread onto sterile NA plates and these plates were then exposed to either 10 ppm ozone concentration or charcoal filtered "clean air" for 2 min. Colony count was determined after incubating NA plates at $37{ }^{\circ} \mathrm{C}$ for $24 \mathrm{~h}$. 


\subsection{Statistical Analysis}

Data were analyzed using SPSS (IBM SPSS Statistics 19 64Bit) and graphs were produced using Microsoft Office Excel 2010 and SigmaPlot 12.5. Normal data distribution was tested using a Normality test and significant differences between mean values were verified using LSD $(p<0.05)$ following one-way ANOVA.

\section{Conclusions}

Exposure to $1 \mathrm{ppm}$ and $10 \mathrm{ppm}$ gaseous ozone treatment for 10 and $2 \mathrm{~min}$, respectively, significantly reduced $E$. coli and Listeria spp. populations on spinach. In addition, the pathogens did not re-grow after treatment, i.e., over a nine-day storage period. Although ozone treatment only reduced bacterial loads by $1 \mathrm{log}$, there is still commercial potential as ozone is easy to produce on site and apply at levels which do not damage sensitive leafy produce. The findings from this study show that some bacteria in populations are resistant to ozone treatment and increasing cell (colony) age of $E$. coli was shown to be linked to enhanced ozone resistance. Further work is needed to better understand the exact mechanism of resistance, and this may lead to determining methods that can overcome resistance. Such applications could deliver immense potential benefits for commercial use and improving public health.

\section{Acknowledgments}

This study was supported by the ADHB/Horticultural Development Company (HDC) (FV 386) via the award of a PhD studentship to Shreya Wani. All E. coli and Listeria spp. strains were kindly provided by Geneius laboratories Ltd. (www.geneiuslabs.com). We thank Matthew Peake for technical help and Alan Craig for maintaining and calibrating the ozone fumigation.

\section{Author Contributions}

The work presented is a part of a $\mathrm{PhD}$ project funded by the UK-ADHB/HDC; the data were managed, designed, collected, and analyzed by Shreya Wani who took the lead on writing the manuscript. Ian Singleton and Jeremy Barnes supervised the work, assisted in experimental design and data interpretation, and won the grant award. Joseph Thompson was a summer intern and assisted with some experimental work in the laboratory. Jagpreet Maker was a post-graduate student who contributed to the editing and approval of the manuscript.

\section{Conflicts of Interest}

The authors declare no conflict of interest.

\section{References}

1. Burnett, S.L.; Beuchat, L.R. Human pathogens associated with raw produce and unpasteurized juices, and difficulties in decontamination. J. Ind. Microbiol. Biotechnol 2000, 25, 281-287. 
2. Abadias, M.; Usall, J.; Anguera, M.; Solsona, C.; Vinas, I. Microbiological quality of fresh, minimally-processed fruit and vegetables, and sprouts from retail establishments. Int. J. Food Microbiol. 2008, 123, 121-129.

3. Velusamy, V.; Arshak, K.; Korostynska, O.; Oliwa, K.; Adley, C. An overview of foodborne pathogen detection: In the perspective of biosensors. Biotechnol. Adv. 2010, 28, 232-254.

4. Olaimat, A.N.; Holley, R.A. Factors influencing the microbial safety of fresh produce: A review. Food Microbiol. 2012, 32, 1-19.

5. Engels, C.; Weiss, A.; Carle, R.; Schmidt, H.; Schieber, A.; Ganzle, M.G. Effect of gallotannin treatment on attachment, growth and survival of Escherichia coli O157:H7 and Listeria monocytogenes on spinach and lettuce. Eur. Food Res. Technol. 2012, 234, 1081-1090.

6. Griffin, P.M.; Tauxe, R.V. The epidemiology of infections caused by Escherichia coli O157:H7, other enterohemorrhagic E.coli, and the associated Hemolytic Uremic Syndrome. Epidemiol. Rev. 1991, 13, 60-99.

7. Tomas-Callejas, A.; Lopez-Velasco, G.; Camacho, A.B.; Artes, F.; Artes-Hernandez, F.; Suslow, T.V. Survival and distribution of Escherichia coli on diverse fresh-cut baby leafy greens under preharvest through postharvest conditions. Int. J. Food Microbiol. 2011, 151, 216-222.

8. Coia, J.E. Clinical, microbiological and epidemiological aspects of Escherichia coli $\mathrm{O} 157$ infection. FEMS Immunol. Med. Microbiol. 1998, 20, 1-9.

9. Farber, J.M.; Peterkin, P.I. Listeria monocytogenes, a Food-Borne pathogen. Microbiol. Rev. 1991, 55, 476-511.

10. Notermans, S.; Todd, E.C.D. Surveillance of listeriosis and its causative pathogen, Listeria monocytogenes. Food Control 2011, 22, 1484-1490.

11. Launders, N.; Byrne, L.; Adams, N.; Glen, K.; Jenkins, C.; Tubin-Delic, D.; Locking, M.; Williams, C.; Morgan, D.; Outbreak Control Team. Outbreak of Shiga toxin-producing E.coli O157 associated with consumption of watercress, United Kingdom, August to September 2013. Euro Surveill. 2013, 18, doi:10.2807/1560-7917.ES2013.18.44.20624.

12. Bower, C.K.; Daeschel, M.A. Resistance responses of microorganisms in food environments. Int. J. Food Microbiol. 1999, 50, 33-44.

13. Mahapatra, A.K.; Muthukumarappan, K.; Julson, J.L. Applications of ozone, bacteriocins and irradiation in food processing: A review. Crit. Rev. Food Sci. Nutr. 2005, 45, 447-461.

14. Singh, N.; Singh, R.K.; Bhunia, A.K.; Stroshine, R.L. Efficacy of chlorine dioxide, ozone, and thyme essential oil or a sequential washing in killing Escherichia coli O157:H7 on lettuce and baby carrots. LWT Food Sci. Technol. 2002, 35, 720-729.

15. Goncalves, A.A. Ozone-An emerging technology for the seafood industry. Braz. Arch. Biol. Technol. 2009, 52, 1527-1539.

16. Tzortzakis, N.; Borland, A.; Singleton, I.; Barnes, J. Impact of atmospheric ozone-enrichment on quality-related attributes of tomato fruit. Postharvest Biol. Technol. 2007, 45, 317-325.

17. Karaca, H.; Velioglu, Y.S. Effects of ozone treatments on microbial quality and some chemical properties of lettuce, spinach, and parsley. Postharvest Biol. Technol. 2014, 88, 46-53.

18. Alwi, N.A.; Ali, A. Reduction of Escherichia coli O157, Listeria monocytogenes and Salmonella enterica sv. Typhimurium populations on fresh-cut bell pepper using gaseous ozone. Food Control 2014, 46, 304-311. 
19. Yuk, H.G.; Yoo, M.Y.; Yoon, J.W.; Marshall, D.L.; Oh, D.H. Effect of combined ozone and organic acid treatment for control of Escherichia coli $\mathrm{O} 157: \mathrm{H} 7$ and Listeria monocytogenes on enoki mushroom. Food Control 2007, 18, 548-553.

20. Fan, L.; Song, J.; McRae, K.B.; Walker, B.A.; Sharpe, D. Gaseous ozone treatment inactivates Listeria innocua in vitro. J. Appl. Microbiol. 2007, 103, 2657-2663.

21. Gleeson, E.; O’Beirne, D. Effects of process severity on survival \& growth of Escherichia coli \& Listeria innocua on minimally processed vegetables. Food Control 2005, 16, 677-685.

22. O'Beirne, D.; Francis, A.G. Effects of the indigenous microflora of minimally processed lettuce on the survival and growth of Listeria innocua. Int. J. Food Sci. Technol. 1998, 33, 477-488.

23. Rico, D.; Martín-Diana, A.B.; Barat, J.M.; Barry-Ryan, C. Extending and measuring the quality of fresh-cut fruit and vegetables: A review. Trends Food Sci. Technol. 2007, 18, 373-386.

24. Alexopoulos, A.; Plessas, S.; Ceciu, S.; Lazar, V.; Mantzourani, I.; Voidarou, C.; Stavropouloua, E.; Bezirtzogloua, E. Evaluation of ozone efficacy on the reduction of microbial population of fresh cut lettuce (Lactuca sativa) and green bell pepper (Capsicum annuum). Food Control 2013, 30, 491-496.

25. Klockow, P.A.; Keener, K.M. Safety and quality assessment of packaged spinach treated with a novel ozone-generation system. LWT Food Sci. Technol. 2009, 42, 1047-1053.

26. Bialka, K.L.; Demirci, A. Decontamination of Escherichia coli O157:H7 and Salmonella enterica on blueberries using ozone and pulsed UV-light. J. Food Sci. 2007, 72, 391-396.

27. Akbas, M.Y.; Ozdemir, M. Application of gaseous ozone to control populations of Escherichia coli, Bacillus cereus and Bacillus cereus spores in dried figs. Food Microbiol. 2008, 25, 386-391.

28. Scifò, G.O.; Randazzo, C.L.; Restuccia, C.; Fava, G.; Caggia, C. Listeria innocua growth in fresh cut mixed leafy salads packaged in modified atmosphere. Food Control 2009, 20, 611-617.

29. Bermúdez-Aguirre, D.; Barbosa-Cánovas, G.V. Disinfection of selected vegetables under nonthermal treatments: Chlorine, acid citric, ultraviolet light and ozone. Food Control 2013, 29, 82-90.

30. Zuma, F.; Lin, J.; Jonnalagadda, S.B. Ozone-initiated disinfection kinetics of Escherichia coli in water. J. Environ. Sci. Health A Tox. Hazard. Subst. Environ. Eng. 2009, 44, 48-56.

31. Vaz-Velho, M.; Silva, M.; Pessoa, J.; Gibbs, P. Inactivation by ozone of Listeria innocua on salmon-trout during cold-smoke processing. Food Control 2006, 17, 609-619.

32. Navarro Llorens, J.M.; Tormo, A.; Martinez-Garcia, E. Stationary phase in gram-negative bacteria. FEMS Microbiol. Rev. 2010, 34, 476-495.

(C) 2015 by the authors; licensee MDPI, Basel, Switzerland. This article is an open access article distributed under the terms and conditions of the Creative Commons Attribution license (http://creativecommons.org/licenses/by/4.0/). 